\title{
Using the Neurofibromatosis Tumor Predisposition Syndromes to Understand Normal Nervous System Development
}

\author{
Cynthia Garcia and David H. Gutmann \\ Department of Neurology, Washington University School of Medicine, Box 8111, 660 South Euclid Avenue, St. Louis, MO 63110, USA \\ Correspondence should be addressed to David H. Gutmann; gutmannd@neuro.wustl.edu
}

Received 19 March 2014; Accepted 7 May 2014; Published 28 August 2014

Academic Editor: Andrea Fuso

Copyright (c) 2014 C. Garcia and D. H. Gutmann. This is an open access article distributed under the Creative Commons Attribution License, which permits unrestricted use, distribution, and reproduction in any medium, provided the original work is properly cited.

\begin{abstract}
Development is a tightly regulated process that involves stem cell self-renewal, differentiation, cell-to-cell communication, apoptosis, and blood vessel formation. These coordinated processes ensure that tissues maintain a size and architecture that is appropriate for normal tissue function. As such, tumors arise when cells acquire genetic mutations that allow them to escape the normal growth constraints. In this regard, the study of tumor predisposition syndromes affords a unique platform to better understand normal development and the process by which normal cells transform into cancers. Herein, we review the processes governing normal brain development, discuss how brain cancer represents a disruption of these normal processes, and highlight insights into both normal development and cancer made possible by the study of tumor predisposition syndromes.
\end{abstract}

\section{Normal Nervous System Development}

The formation of the nervous system requires a highly orchestrated series of events involving cell division, differentiation, death, migration, and intercellular communication (Figure 1). During embryonic and fetal life, the brain and spinal cord originate from a pool of neural stem cells (NSCs) with the capacity to self-renew as well as to give rise to more specialized cells. Self-renewal is the process by which a single stem cell divides to generate one (asymmetric division) or two (symmetric division) daughter stem cells with identical properties as the original mother cell. During cell division, NSCs must enter the cell cycle and replicate their DNA (S phase) prior to forming two daughter cells through mitosis (M phase). During asymmetric division, central nervous system (CNS) NSCs generate restricted progenitor cells (glial or neural progenitors) with more limited differentiative capacity. In this manner, glial progenitor cells give rise to oligodendrocytes or astrocytes, while neural progenitors give rise to neurons. The fate division that dictates the formation of two identical NSCs versus a cell lineage-restricted progenitor is a highly regulated process.
Following cell specialization, there are defined periods of cell migration, in which neurons, astrocytes, and oligodendrocytes (or their progenitors) move to particular positions within the developing brain and spinal cord. The orderly migration of neurons to specific layers (laminae) is essential for the proper organization of the brain and for the formation of functional neuronal connections $[1,2]$. Failure to migrate to the right place at the right time can result in the generation of ectopically located neurons, which can cause seizures or cognitive deficits $[3,4]$.

In addition to cell division and differentiation, there are periods during embryonic development when excess numbers of cells must be culled. This well-ordered process requires the enactment of a programmed cell death pathway (apoptosis). Apoptosis is necessary for the proper spacing and orientation of neurons and for generating spaces like the ones between fingers and toes $[5,6]$. During programmed cell death, the nucleus becomes fragmented and the cellular membranes are disrupted, causing the cell to break up into vesicles (apoptotic bodies), which are then removed by other cells by phagocytosis. 


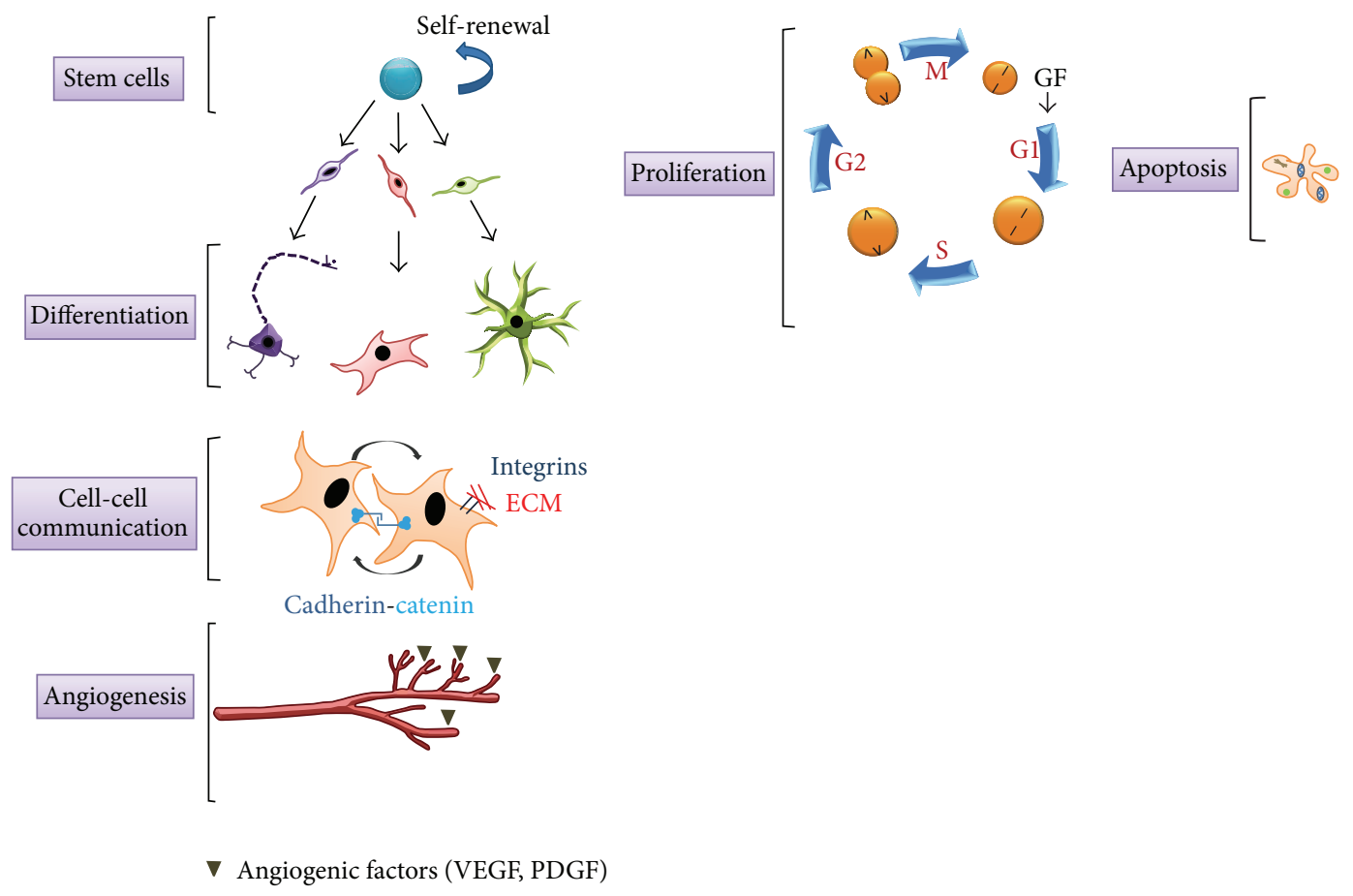

FIGURE 1: Normal brain development. The nervous system develops from neural stem cells (NSCs) capable of self-renewal, which can divide and generate cells with equal developmental potential. These NSCs also generate differentiated cell types, such as glial-restricted and neuronrestricted progenitors, which further give rise to astrocytes, oligodendrocytes, and neurons. The expansion of progenitors and their progeny is dependent on orderly cell cycle progression and controlled escape from programmed cell death (apoptosis). Developing cells also form cell-cell interactions through cell adhesion molecules, which transmit regulatory signals to influence cell growth and migration. Finally, both progenitor and differentiated cell types actively induce the formation of blood vessels to provide oxygen and nutrients.

Intercellular communication is likewise necessary to establish a functional nervous system, as it provides a way for cells to receive instructive cues from neighboring cells. These instructions can be delivered by soluble molecules (e.g., growth factors and cytokines) or by membrane-bound ligands (e.g., integrins). Soluble cues establish gradients for directed cell migration or signal to recipient cells via plasma membrane receptor tyrosine kinases (RTKs). These RTKs transduce the extracellular signals by activating intracellular signaling pathways through the sequential phosphorylation of downstream effector molecules (e.g., RAF and PI3-Kinase).

Finally, during brain development, progenitor and more differentiated cells actively induce the formation of new blood vessels to provide oxygen and nutrients crucial for cell function and survival. The formation of blood vessels comprises two distinct steps: vasculogenesis, the de novo formation of blood vessels, and angiogenesis, the sprouting of preexisting blood vessels. Both vasculogenesis and angiogenesis are elicited by angiogenic factors, such as vascular endothelial growth factor (VEGF) and platelet-derived growth factor (PDGF) that bind to transmembrane RTKs on endothelial cells $[7,8]$. During development, there is higher expression of these angiogenic factors, returning to lower levels once mature tissues have formed.

As might be predicted for a highly organized tissue, defects in any of these processes during specific times of brain development can lead to abnormal cell growth (tumors), brain malformations (lissencephaly and heterotopias), or intellectual disabilities (autism) [9-11]. In an effort to identify the key cellular and molecular determinants that underlie normal brain development, researchers have often turned to inherited conditions in which affected individuals exhibit abnormalities in brain development: for example, children with lissencephaly harbor mutations in the LIS1 gene and are born with a brain malformation characterized by defects in the normal folded architecture of the cortex [12]. Using mouse models of lissencephaly, this brain abnormality ("smooth" cortex) is due to impaired migration of neurons into the developing brain $[13,14]$. Similarly, individuals with tuberous sclerosis complex (TSC) develop a wide range of brain pathology, including abnormal collections of neurons (heterotopias), due to a mutation in the TSC1 or TSC2 gene [15]. Using mice with brain $T s c l$ gene inactivation, these heterotopias were shown to result from abnormal migration of neural progenitor cells into the rostral migratory stream and olfactory bulb $[16,17]$ as a direct consequence of increased activation of the Rheb GTPase molecule, a downstream effector of the TSC protein complex [18]. In addition, individuals with a germline mutation in the PTEN gene develop Lhermitte-Duclos disease (LDD), a neurological condition characterized by dysplastic gangliocytomas (benign neuronal overgrowths), leading to seizures $[19,20]$. Using Pten knockout mouse strains, loss of PTEN function results in increased granule neuron size, defects in 


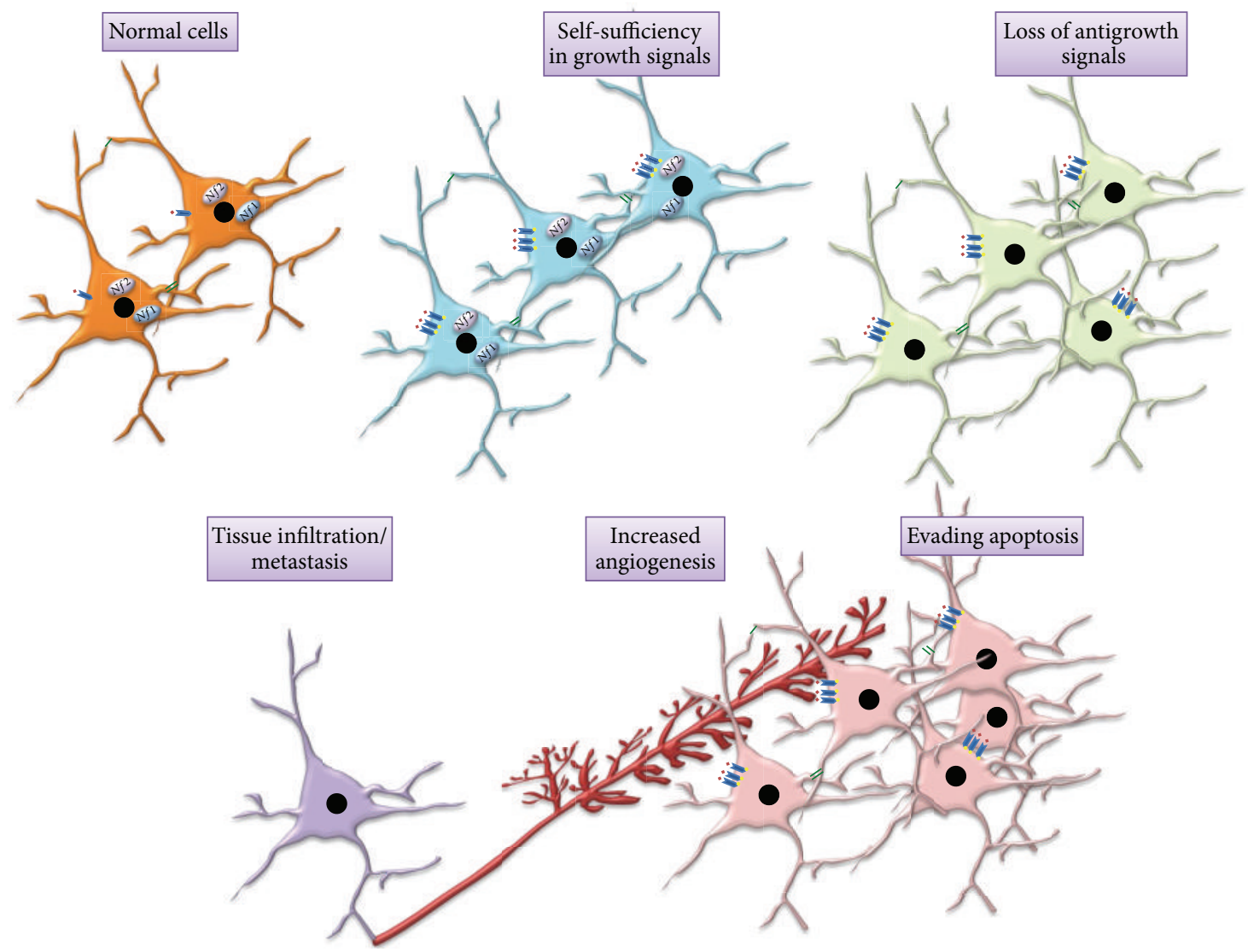

FIGURE 2: Cancer requires the deregulation of several normal developmental processes. Cells acquire at least five alterations that collectively lead to cancer: self-sufficiency in growth signals, loss of antigrowth signals, evasion of apoptosis, increased angiogenesis, and inappropriate tissue invasion. Tumor development begins when a cell (either a stem cell or a differentiated cell) acquires a mutation that increases its propensity to proliferate and decreases its ability to undergo apoptosis. Cell-cell interactions become subsequently deregulated to allow cancer cells to promote angiogenesis and tissue invasion (metastasis).

neuronal migration and brain patterning, and abnormalities in synaptic structure due to hyperactivation of the PTENregulated protein, protein kinase B (AKT) [21-23]. Finally, Rett syndrome is characterized by microcephaly, autism, and developmental regressions in early childhood as a result of mutations in the MECP2 gene [24, 25]. Although the exact molecular and cellular mechanisms underlying Rett syndrome pathogenesis have not been completely elucidated, studies employing genetically engineered mice have shown that loss of $\mathrm{MeCP} 2$ function results in decreased dendritic spine density and defects in GABAergic transmission [26, 27].

\section{Cancer as a Disease of Deregulated Development}

There are many reasons to view cancer as a disease of abnormal development. Cancer requires that the cellular processes essential for normal nervous system development become deregulated (Figure 2). In many tissue types in the body, secreted signaling (paracrine) factors have been identified that either stimulate or inhibit progression through the cell cycle. Mitogenic paracrine factors (growth factors) act at the $G_{1}$ to $S$-phase transition of the cell cycle by binding to their cognate growth factor receptors. Growth factor receptor engagement leads to conformational changes in the receptors and phosphorylation of specific residues in the intracellular portions of the molecule to promote the binding and activation of downstream signaling intermediates $[28,29]$. Whereas normal cells divide in response to growth factor stimulation, tumor cells liberate themselves of these constraints in one of four ways. (1) Cancer cells may acquire the ability to synthesize their own growth factors, such as epidermal growth factor (EGF) and PDGF $[30,31]$, to stimulate growth in an autocrine fashion. (2) Neoplastic cell types may overexpress a particular growth factor receptor $[32,33]$ or express one with a constitutively active mutation $[34,35]$, leading to enhanced responsiveness to available growth factors or growth factor-independent growth, respectively. (3) Cancer cells can also acquire selfsufficiency through abnormal expression or function of integrins [36]. Integrins are transmembrane receptors that link the extracellular matrix (ECM) to the cytoskeleton, transmitting both mechanical and chemical signals. Whereas normal cells employ integrins to remain in a quiescent state $[37,38]$, cancer cells with dysfunctional integrin signaling allow for enhanced survival, proliferation, and migration 
[39-41]. (4) The effector proteins downstream of RTKs or integrins can be mutationally activated to lead to constitutive growth signaling in the absence of growth factors or integrins. Examples of these protooncogenes, including Ras, Src, and Raf, have all been mutated in human cancers [42-44]. Each of these protooncogenes, when mutationally activated, can initiate cancer in experimental model systems [45-47].

Another reason to view cancer as a disease of development is that tumor cells sometimes disable the proteins that negatively control normal cell growth. This escape can be mediated in part through loss of tumor suppressor gene function. Tumor suppressors inhibit cell proliferation by suppressing protooncogene function, thus preventing them from activating their downstream effector proteins to promote cell growth. In this manner, PTEN negatively controls AKT activity, such that loss of Pten gene expression results in increased AKT signaling and cell growth. In addition, tumor suppressor proteins control the function of cyclins required for orderly cell cycle progression, and their mutational inactivation (e.g., retinoblastoma) deregulates cyclin function and leads to higher levels of proliferation [48, 49].

Moreover, tumor growth may also result from an escape from normal programmed cell death. Activation of either of the two apoptotic pathways (extrinsic and intrinsic) can initiate cell death through the sequential activation of caspases (cysteine-aspartic acid proteases). Whereas the engagement of the extrinsic pathway requires ligand activation of death receptors, the intrinsic pathway involves Bcl-2 family member-mediated mitochondrial cytochrome-c release [50]. Engagement of the apoptotic machinery is observed following mutational inactivation of the TP53 tumor suppressor gene; however, mutations in negative regulators of the PI3Kinase/AKT pathway also provide prosurvival signals by inhibiting Bcl-2 family member function [51]. As such, loss of function mutations in the PTEN and NF1 tumor suppressor genes leads to increased AKT activity and attenuated apoptosis $[52,53]$.

During embryogenesis, cells obtain oxygen and nutrients from the developing vasculature, formed in response to angiogenic factors like VEGF and PDGF $[54,55]$. Similar to development, tumors are maintained by the formation of new blood vessels (neoangiogenesis). In this regard, cancer cells elaborate the same angiogenic factors [56] that produce blood vessel growth in the embryo to promote increased oxygen and nutrient delivery.

Another acquired property of tumors is tissue invasion, through both local spread (infiltration) and distant seeding (metastasis). In order to accomplish this, neoplastic cells must undergo a cascade of events that allow the cells to leave the primary tumor site. First, cells develop alterations in their shape as well as attachment to one another and to the ECM through loss of cell-to-cell interactions and/or cellto-ECM adhesion molecules. Loss of cell-to-cell adhesion allows dissociation from the original tumor, enhanced cell locomotion, and infiltration of surrounding tissue. Disrupted cell-to-cell adhesion and infiltration have been shown in Ecadherin and N-cadherin knockout mouse models $[57,58]$. Similarly, adhesion molecules associated with cell migration during embryogenesis also facilitate cell migration and infiltration in neoplastic cells when deregulated. For example, overexpression of $\mathrm{N}$-cadherin in breast cancer cells promotes increased cell motility and infiltration [59]. In addition, integrins also associate with RTKs to activate signaling pathways necessary for cell migration. For metastasis to occur, tumor cells must enter blood vessels, at which point they travel to distant sites, and then exit the blood vessels to seed these new sites. This process involves paracrine signaling between RTKs (e.g., colony stimulating factor-1 receptor: CSF1R) on macrophages and EGFR on tumor cells [60]. A final step in cancer malignancy involves the outgrowth of these secondary tumors at these remote sites. There are at least twelve known metastasis suppressor genes that inhibit invasion and metastasis, including the Raf kinase inhibitor protein (RKIP) molecule, the dysfunction of which promotes invasion and metastasis of cancer cells in a Raf/MEK-dependent manner $[61,62]$.

Beyond these cell intrinsic factors, other elements also contribute to tumor formation, including biophysical forces [63], endocrine disruptors [64], and non-neoplastic cells in the tumor microenvironment $[65,66]$. The importance of these stromal cells (macrophages, endothelial cells, and reactive astrocytes) to nervous system tumorigenesis as well as tumor maintenance has led to the identification of numerous cytokines and growth factors $[67,68]$ critical to the genesis and growth of these cancers. As such, the nonneoplastic cell types and growth signals that exist in the tumor microenvironment represent logical targets for therapeutic drug design $[69,70]$.

In the following sections, we will use two nervous system tumor predispositions, neurofibromatosis type 1 (NF1) and neurofibromatosis type 2 (NF2), to illustrate the overlap between cancer and normal development and to demonstrate how these inherited syndromes provide instructive insights for developmental neurobiologists and neuro-oncologists alike.

\section{Neurofibromatosis Type 1}

NF1 is an autosomal dominant inherited cancer predisposition syndrome that affects 1 in 2,500 individuals worldwide [71]. Similar to other inherited cancer syndromes [72], individuals with NF1 are born with a mutated (nonfunctional) copy of the NF1 gene in all cells in their body. Tumors arise following somatic gene inactivation of the remaining functional $N F 1$ allele in specific cell types, leading to complete loss of neurofibromin function in those cells. As would be expected from a cancer predisposition syndrome, individuals with $\mathrm{NF} 1$ are prone to the development of benign and malignant tumors, in this case, affecting the peripheral nervous system (PNS) and central nervous system (CNS). As such, people with NF1 develop optic pathway gliomas, neurofibromas, and malignant peripheral nerve sheath tumors [73-75]. Optic pathway gliomas are glial cell tumors detected in about 15\% of children with NF1, typically in individuals younger than seven years of age [73]. When symptomatic, optic pathway gliomas cause impairments in vision or blindness.

Neurofibromas are benign Schwann cell tumors that begin to appear during adolescence, arising anywhere in 


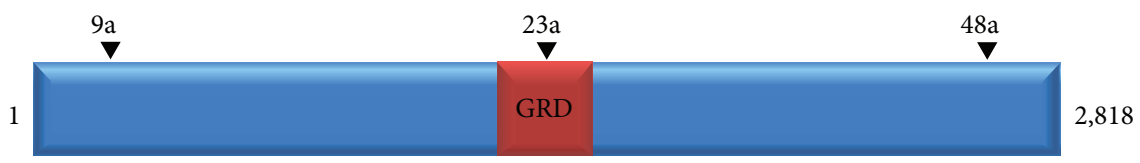

(a)

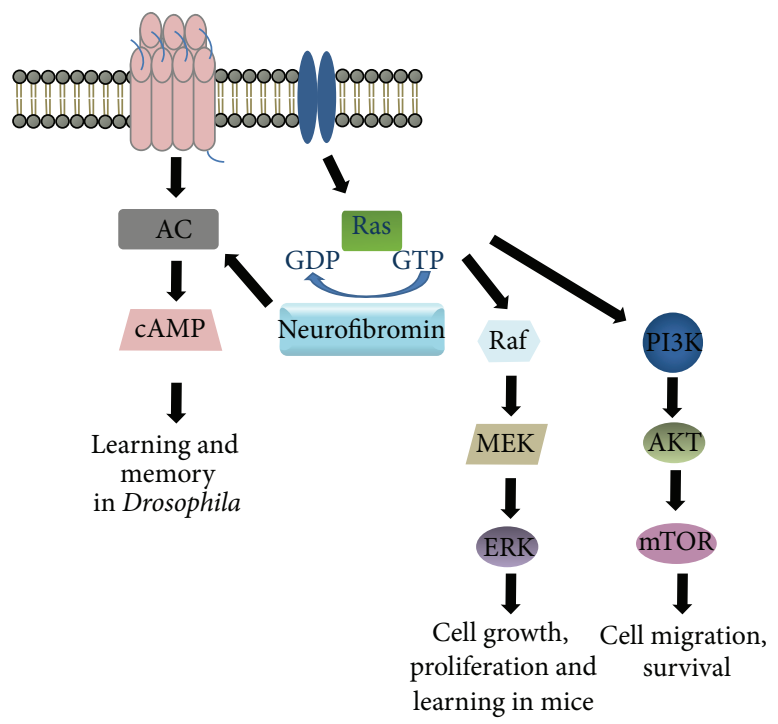

(b)

FIGURE 3: Neurofibromin structure and function. (a) Neurofibromin is a 2,818-amino-acid cytoplasmic protein with three alternatively spliced exons (9a, 23a, and 48a) and a central GAP-related domain (GRD). GAPs are negative regulators of RAS by accelerating the conversion of active GTP-bound RAS to its inactive GDP-bound form. (b) Loss of neurofibromin function leads to increased RAS pathway (RAF/MEK/ERK or PI3K/AKT/mTOR) signaling as well as reduced cAMP generation.

the body as cutaneous, subcutaneous, or deeply located masses [76]. A more diffuse type of neurofibroma, the plexiform neurofibroma, is often detected in very young children, where they can grow to significant proportions and cause morbidity through compression of surrounding tissues [77]. Less commonly, plexiform neurofibromas transform into malignant peripheral nerve sheath tumors (MPNSTs) [78]. These sarcoma-type cancers are highly metastatic and typically unresponsive to conventional therapies [79].

\section{NF1 Gene Structure and Function}

The NF1 gene is located on chromosome 17q11.2 and codes for a 2,818-amino-acid protein called neurofibromin [80] (Figure 3(a)). Neurofibromin is a large cytoplasmic molecule with three differentially spliced exons (9a, 23a, and 48a) that may be important for neurofibromin function in specific cell types [81-85]. Inspection of the predicted coding sequence reveals that neurofibromin contains a small 300amino-acid domain with significant homology to guanosine triphosphatase- (GTPase-) activating proteins (GAPs) involved in the negative regulation of the RAS small GTPase proto-oncoprotein. In this regard, neurofibromin negatively regulates RAS activity by accelerating the hydrolysis of active GTP-bound RAS to inactive GDP-bound RAS [86].

In NF1-associated tumors, neurofibromin loss leads to Ras hyperactivation and increased signaling through the Ras downstream effector proteins, RAF/MEK (ERK pathway) and PI3-Kinase (PI3K)/AKT (Figure 3(b)). While ERK has been implicated in cell proliferation control, AKT signaling is important for promoting cell migration and survival. Both pathways have been implicated in Nf1-deficient cell growth and proliferation [53, 87-89]. Furthermore, neurofibromin is also an important regulator of cyclic AMP (cAMP), which has been implicated in learning and memory. Studies in Drosophila have shown that the $N f 1$ gene is required for activation of the adenylyl cyclase/cAMP pathway, which mediates learning and memory [90]. In mice, decreased cAMP activity due to neurofibromin loss or reduction results in increased astrocyte proliferation [91] as well as attenuated CNS axon length and survival [92].

Hyperactivation of the signaling pathways that govern NF1-associated tumor growth can result from growth factors or cytokines produced by non-neoplastic cells in the tumor microenvironment. The dependence on these stromal cells and growth factors is nicely illustrated by $N f 1$ mouse models of plexiform neurofibroma and optic glioma [93]. In these genetically engineered mouse strains, loss of $\mathrm{Nf1}$ gene expression in neoplastic Schwann cell or neuroglial progenitors alone is not sufficient for plexiform neurofibroma [94] or optic glioma $[95,96]$ formation, respectively. Instead, tumorigenesis requires complete $N f 1$ inactivation in progenitors to be coupled with reduced $N f 1$ gene expression ( $N f 1+/-$ mice). Whereas plexiform neurofibromas require $N f 1+/-$ mast cells 


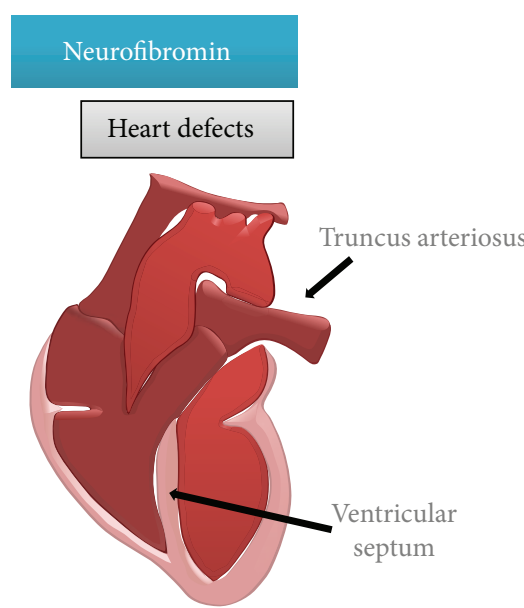

(a)

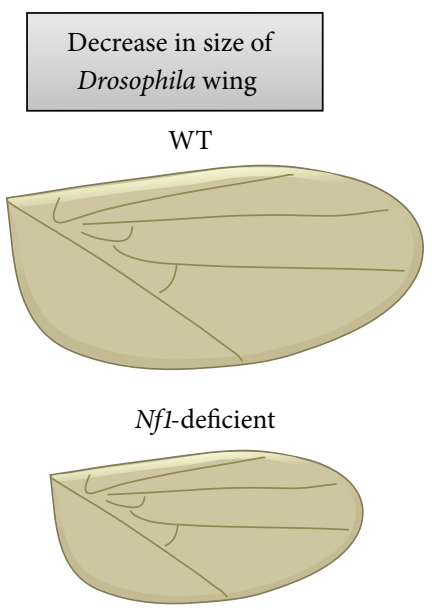

(b)
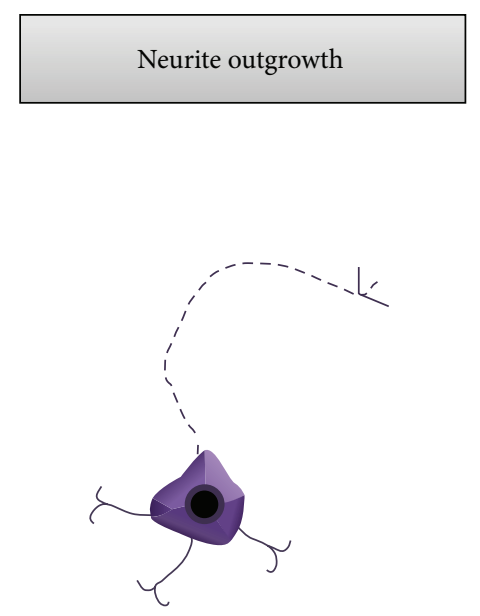

(c)

Figure 4: Neurofibromin function during normal development. Neurofibromin is important for proper (a) heart vessel development, (b) Drosophila wing formation (cell proliferation and size), and (c) axon extension and neuron survival.

[97, 98], optic glioma formation and continued growth are dependent on $\mathrm{Nf1+/}$ - microglia [99-101]. The growth factors produced by these stromal cells have recently been targeted in preclinical mouse studies with encouraging early results $[98,102]$.

\section{Neurofibromin Function during Normal Nervous System Development}

The critical role of the $N f 1$ gene in normal development is underscored by several observations made in genetically engineered mice. Complete loss of neurofibromin in mice results in embryonic lethality between days E12.5 and E13.5. The cause of death in these Nf1-deficient embryos is the consequence of a defect in cardiac vessel formation (Figure 4(a)). Instead of having a separate aorta and pulmonary artery, these mice have a single outflow tract, known as double outlet right ventricle [103]. This defect is caused by abnormal Nf1deficient cardiac neural crest cell migration.

Owing to the lethality that results from complete NfI gene inactivation in mice, insights into the importance of neurofibromin during development have derived from the use of $N f 1$ mutant flies and $N f 1$ conditional knockout mice (CKO). Loss of Nf1 gene expression in Drosophila results in a $25 \%$ reduction in wing size (Figure 4 (b)) and in the overall size of larvae, pupae, and adults [104]. This small size defect is not restored by manipulating RAS signaling but rather is rescued by overexpression of activated protein kinase A (PKA). The rescue by PKA, and not by RAS, supports the notion that neurofibromin positively regulates cAMP independent of RAS and that some of the NFl-associated phenotypes may reflect reduced cAMP levels. Studies in mice have also shown that neurofibromin positively regulates cAMP activity [91, 105]. In this regard, the use of Nf1 CKO mice in which neurofibromin loss occurs in $\mathrm{BLBP}^{+}$progenitor cells or $\mathrm{Nfl}+\mathrm{l}-$ primary CNS neurons has demonstrated that neurofibromin is critical for axonal extension and neuronal survival in a cAMP-dependent manner (Figure 4(c)) $[92,106$, 107].

In addition, neurofibromin is an important regulator of NSC function [107, 108]. As such, Nf1 gene inactivation results in increased proliferation of spinal cord progenitors [109], brainstem NSCs [89], and telencephalic NSCs [108]. The mechanism underlying neurofibromin regulation of CNS NSC function involves control of RAS signaling.

Lastly, neurofibromin is also important for neuronal and glial differentiation in the brain. In this regard, $\mathrm{Nfl}$ CKO mice in which the Nf1 gene is inactivated in E12.5 GFAP ${ }^{+}$cortical progenitors exhibit a significant reduction in patterning of cortical cells into whisker barrels throughout the somatosensory cortex [110]. This patterning defect was shown to result from increased RAS/ERK signaling. Similarly, NfI CKO mice in which Nfl is inactivated in neurons have reduced cortical thickness [111]. In contrast, neurofibromin regulates brain glial differentiation (gliogenesis) in a RAS/mammalian target of rapamycin (mTOR)-dependent manner $[89,107]$.

\section{Neurofibromatosis Type 2}

NF2 is also an autosomal dominant inherited cancer predisposition syndrome, caused by a germline mutation in the NF2 gene. Whereas the hallmark of this disorder is bilateral vestibular (VIIIth cranial nerve) schwannoma development, individuals with NF2 also harbor other cranial and peripheral nerve schwannomas, meningiomas, and spinal ependymomas. Teenagers and adults may come to medical attention when they present with hearing loss, balance problems, weakness, or seizures secondary to tumor development and progression. Similar to other cancer predisposition syndromes, tumors arise following somatic NF2 gene inactivation in specific cell types to render both copies of the NF2 gene nonfunctional in those cells $[112,113]$. The importance of the NF2 gene to nervous system tumor formation is further underscored by the finding that NF2 


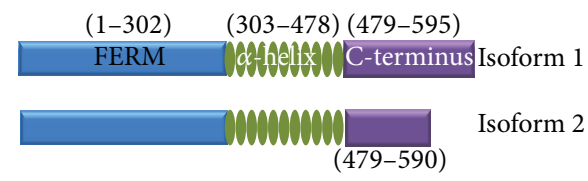

(a)

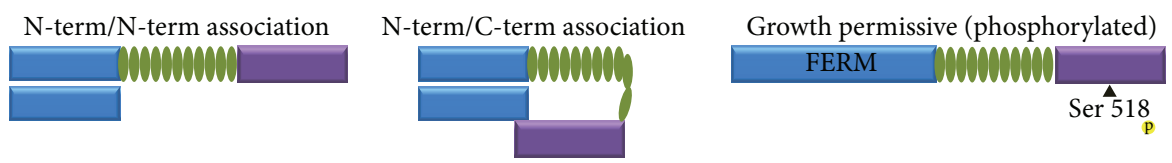

(b)

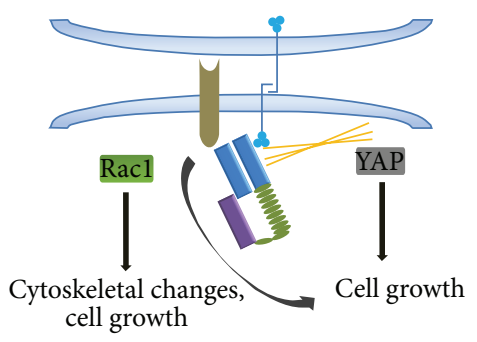

(c)

FIGURE 5: Merlin structure and function. (a) Merlin is a 595- (or 590-) amino-acid protein composed of three structural regions: an amino terminal domain (FERM), an $\alpha$-helix domain, and a carboxyl terminal domain (CTD). There are two merlin isoforms. Isoform 1 contains exon 17 and lacks exon 16. Isoform 2 contains exon 16, which inserts 11 unique c-terminal amino acids followed by a termination codon that prevents the translation of exon 17. (b) Merlin forms an intramolecular complex in which the FERM domain associates with the CTD. Phosphorylation of merlin at Serine-518 results in an open conformation, which inactivates the tumor suppressor activity of merlin. (c) Merlin binds to the actin cytoskeleton, RTKs, and CD44 to form proper adherens junctions. It also inhibits RAC1 and YAP activity, which are important for normal growth regulation.

locus alterations predominate in sporadic (non-NF2-related) schwannomas, meningiomas, and ependymomas [114-118]. Collectively, these clinical observations indicate that the NF2 gene is a key regulator of normal cell function in Schwann cells, meningeal cells, and spinal ependymal cells.

\section{NF2 Gene Structure and Function}

The NF2 gene is located on chromosome $22 \mathrm{q}$ and encodes a 595-amino-acid tumor suppressor protein called either merlin or schwannomin $[119,120]$ (Figure 5(a)). The predicted merlin protein sequence reveals three structural domains, including an amino terminal FERM (four-point one, ezrin, radixin, and moesin) domain (residues 1-302), a central alpha helical region (residues 303-479), and a carboxyl terminus region (480-595). Based on this predicted structure, merlin belongs to the band 4.1 superfamily of proteins that link the actin cytoskeleton to cell surface glycoproteins [121]. There are two isoforms of merlin that differ in their alternative use of exon 16 (isoform 2; missing exon 17) versus exon 17 (isoform 1 ; missing exon 16) $[122,123]$. Whereas merlin isoform 1 is critical for growth regulation and tumorigenesis [124], recent studies have shown that merlin isoform 2 has a key role in peripheral nerve function $[125,126]$.

Merlin has been hypothesized to exist in either a closed, active state or an open, inactive state mediated by FERM domain/carboxyl terminal domain (CTD) intramolecular binding (Figure 5(b)). Phosphorylation of merlin at several residues, including Serine-518, is thought to inhibit FERM/CTD binding, resulting in the open, inactive configuration. As such, merlin functions as a tumor suppressor in the closed, active state, when the CTD can associate with the FERM domain $[124,127,128]$. While this model may explain merlin growth regulation, other mechanisms must be operative in mediating merlin isoform 2 function.

Unlike neurofibromin, the precise mechanism by which merlin regulates cell growth and motility has not been fully solved. The divergent findings made in different laboratories using different model systems may reflect tissue- or cell type-specific roles for merlin (Figure 5(c)). Merlin functions as a regulator of cytoskeletal dynamics, whereas in other cell types, it regulates the formation of adherens junctions [129] and controls cell motility [130]. For example, complete Nf2 gene inactivation in mouse embryo fibroblasts (MEFs) results in defective cadherin-mediated intercellular (cell-tocell) adhesion, such that $\beta$-catenin, a component of adherens junctions, is no longer localized along cell-cell borders [129]. This merlin-regulated contact-mediated growth arrest occurs by coupling cell surface adhesion molecules (e.g., E-cadherin) to transmembrane RTKs (e.g., the EGF receptor). In this manner, merlin strengthens cadherin-mediated intercellular attachments to control growth factor receptor internalization and mitogenic signaling [131, 132]. The ability of merlin to suppress growth factor receptor function also operates at the level of receptor activation (e.g., ErbB2) [133] or by regulating 


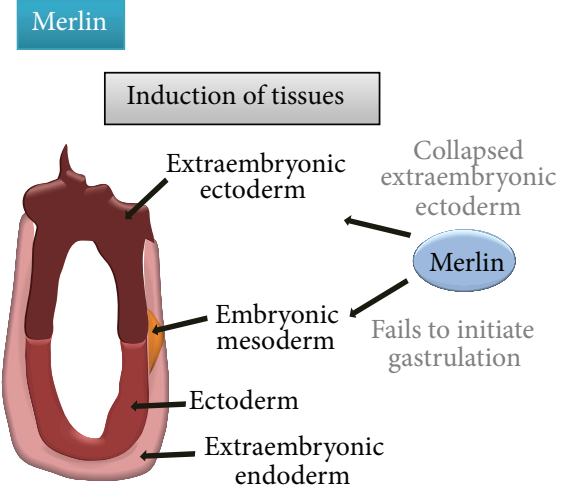

(a)

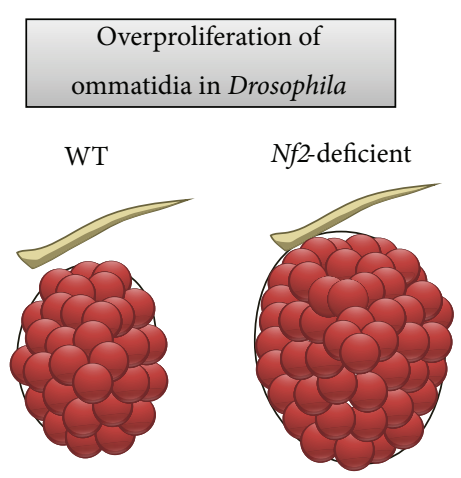

(b)

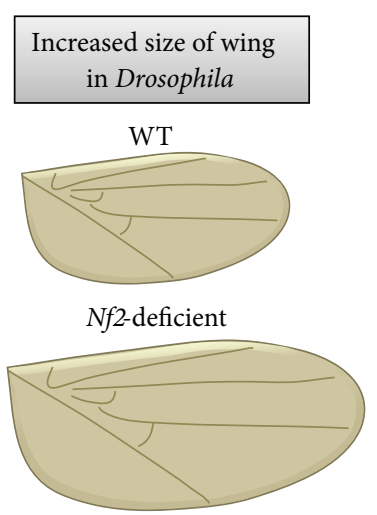

(c)

Figure 6: Merlin function during normal development. (a) Merlin is required for the induction of tissue layers during early embryonic development. In addition, merlin is essential for normal control of ommatidia proliferation (b) and (c) wing size in Drosophila.

the abundance or availability of growth factor receptors at the cell surface [134]. While the precise mechanism underlying merlin regulation of cytoskeletal dynamics or adherens junction signaling has not been completely elucidated, merlin negatively regulates the activity of Racl $[128,135]$, a small GTPase protein important for actin assembly and lamellipodia formation [136].

Moreover, merlin also functions as a negative regulator of Hippo/Yes-associated protein (YAP) signaling. When active, the transcriptional activator YAP interacts with the adherens junction protein, $\alpha$-catenin [137]. However, following pathway activation, YAP translocates to the nucleus to induce the expression of proteins involved in cell cycle progression $[138,139]$. Because merlin regulates the formation of adherens junctions, it is possible that loss of merlin function results in destabilized adherens junction structures and leads to the nuclear translocation of YAP and the promotion of cell growth. Consistent with this model, merlin negatively regulates cell growth by inhibiting YAP activation both in vitro [140] and in vivo [141].

\section{Merlin Function during Normal Nervous System Development}

The importance of merlin to normal development has been revealed by studies demonstrating that mouse embryos homozygous for an inactivating $\mathrm{Nf2}$ gene mutation die during early embryonic development (E6.5-7.0) [142]. These mice exhibit a collapsed extraembryonic region and a disorganized extraembryonic ectoderm [142] (Figure 6(a)). In addition, $\mathrm{Nf2}$ knockout mice lack expression of mesodermal markers, supporting a defect in the initiation of gastrulation [142].

In Drosophila, merlin is a critical regulator of the structural elements of the developing eye (ommatidia), such that loss of merlin results in increased ommatidia cell proliferation [143] (Figure 6(b)). Moreover, these Nf2 mutant flies have increased overall wing size (Figure 6(c)). The observation that Nf2-deficient cells exhibit increased BrdU incorporation and a change in phosphohistone $\mathrm{H} 3$ and cyclin E expression [144] supports a defect in growth regulation during development.
Similar to neurofibromin, merlin is also important for normal NSC function. As such, merlin is essential for maintaining the hematopoietic stem cell (HSC) niche. Inactivation of the Nf2 gene in HSCs results in increased proliferation, owing to increased bone marrow vascularity [145]. Merlin also functions as a negative regulator of liver progenitor cell function. Liver-specific $N f 2$ gene deletion leads to increased liver progenitor cell proliferation [146]. In the CNS, merlin inhibits the proliferation of neural progenitor cells (NPCs) in the dorsal telencephalon. Using a CKO mouse in which the $\mathrm{Nf2}$ gene was deleted in telencephalic $\mathrm{EMXl}^{+}$cells, merlin loss leads to NPC overproliferation, causing a thicker neocortex [147]. In these mice, neuronal differentiation was reduced, leading to a significant reduction in the size of the hippocampus in a YAP-dependent manner. These findings support the notion that proper merlin function is necessary to limit the expansion of NPCs and promote the differentiation of hippocampal progenitor cells.

In the peripheral nervous system, merlin has been shown to be a negative regulator of Schwann cell myelination. Using Nf2 Schwann cell CKO mice, increased Racl activation in Schwann cells, a signaling pathway previously implicated in normal myelination, was observed [148-151]. This defect caused smaller sciatic nerves, resulting in hindlimb dysfunction [151]. In addition, merlin isoform 2 has a unique function in maintaining peripheral axonal integrity by modulating Ras homolog gene family member A (RHOA) activity [126], further demonstrating both isoform and tissue-specific requirements for merlin during normal development.

\section{Conclusions}

Normal brain development involves a rigorously coordinated series of cellular processes, including properly regulated cell growth, balanced by cell proliferation and cell death, coupled with cell differentiation, migration, and connectivity, which are all essential for the initial formation and life-long maintenance of the mammalian nervous system. Disruptions in any of these tightly controlled events could have devastating consequences. In this manner, inappropriate 
stem cell (progenitor) expansion, glial lineage differentiation, and tissue invasion could set the stage for tumor initiation and malignant progression. By identifying the extracellular cues and intracellular signal transduction pathways that govern normal nervous system development, there is a unique opportunity not only to understand the healthy brain, but also to define how their deregulation contributes to tumorigenesis. The bidirectional information flow between insights derived from developmental neurobiology and those from neuro-oncology creates cross-informative platforms for increasing basic science knowledge and facilitating clinical translation. Leveraging the differences between brain cancer and normal brain homeostasis will be important in designing future effective treatments that target the tumor but spare the normal central nervous system.

\section{Conflict of Interests}

The authors declare that there is no conflict of interests regarding the publication of this paper.

\section{References}

[1] H. J. Kwon, S. Ma, and Z. Huang, "Radial glia regulate CajalRetzius cell positioning in the early embryonic cerebral cortex," Developmental Biology, vol. 351, no. 1, pp. 25-34, 2011.

[2] G. Miyoshi and G. Fishell, "GABAergic interneuron lineages selectively sort into specific cortical layers during early postnatal development," Cerebral Cortex, vol. 21, no. 4, pp. 845-852, 2011.

[3] J. C. Beal, "Case report: neuronal migration disorder associated with chromosome 15q13.3 duplication in a boy with autism and seizures," Journal of Child Neurology, 2013.

[4] B. Korkmaz, G. Benbir, and V. Demirbilek, "Migration abnormality in left cingulate gyrus presenting with autistic disorder," Journal of Child Neurology, vol. 21, no. 7, pp. 600-604, 2006.

[5] W. R. Kim, O. H. Park, S. Choi et al., "The maintenance of specific aspects of neuronal function and behavior is dependent on programmed cell death of adult-generated neurons in the dentate gyrus," European Journal of Neuroscience, vol. 29, no. 7, pp. 1408-1421, 2009.

[6] S. Pajni-Underwood, C. P. Wilson, C. Elder, Y. Mishina, and M. Lewandoski, "BMP signals control limb bud interdigital programmed cell death by regulating FGF signaling," Development, vol. 134, no. 12, pp. 2359-2368, 2007.

[7] B. Millauer, S. Wizigmann-Voos, H. Schnürch et al., "High affinity VEGF binding and developmental expression suggest flk-1 as a major regulator of vasculogenesis and angiogenesis," Cell, vol. 72, no. 6, pp. 835-846, 1993.

[8] P. U. Magnusson, C. Looman, A. Åhgren, Y. Wu, L. ClaessonWelsh, and R. L. Heuchel, "Platelet-derived growth factor receptor- $\beta$ constitutive activity promotes angiogenesis in vivo and in vitro," Arteriosclerosis, Thrombosis, and Vascular Biology, vol. 27, no. 10, pp. 2142-2149, 2007.

[9] P. Gibson, Y. Tong, G. Robinson et al., "Subtypes of medulloblastoma have distinct developmental origins," Nature, vol. 468, no. 7327, pp. 1095-1099, 2010.

[10] J. H. Goodman and M. E. Gilbert, "Modest thyroid hormone insufficiency during development induces a cellular malformation in the corpus callosum: a model of cortical dysplasia," Endocrinology, vol. 148, no. 6, pp. 2593-2597, 2007.
[11] J. J. LeBlanc and M. Fagiolini, "Autism: a "critical period" disorder?” Neural Plasticity, vol. 2011, Article ID 921680, 17 pages, 2011.

[12] A. Mokánszki, I. Körhegyi, N. Szabó et al., "Lissencephaly and band heterotopia: LIS1, TUBA1A, and DCX mutations in Hungary," Journal of Child Neurology, vol. 27, no. 12, pp. 15341540, 2012.

[13] S. Hippenmeyer, Y. H. Youn, H. M. Moon et al., "Genetic mosaic dissection of Lisl and Ndell in neuronal migration," Neuron, vol. 68, no. 4, pp. 695-709, 2010.

[14] M. F. McManus, I. M. Nasrallah, M. M. Pancoast, A. WynshawBoris, and J. A. Golden, "Lis1 is necessary for normal non-radial migration of inhibitory interneurons," The American Journal of Pathology, vol. 165, no. 3, pp. 775-784, 2004.

[15] G. Arca, E. Pacheco, I. Alfonso, M. S. Duchowny, and S. J. Melnick, "Characteristic brain magnetic resonance imaging (IMR) finding in neonates with tuberous sclerosis complex," Journal of Child Neurology, vol. 21, no. 4, pp. 280-285, 2006.

[16] D. M. Feliciano, T. Su, J. Lopez, J. C. Platel, and A. Bordey, "Single-cell Tscl knockout during corticogenesis generates tuber-like lesions and reduces seizure threshold in mice," Journal of Clinical Investigation, vol. 121, no. 4, pp. 1596-1607, 2011.

[17] D. M. Feliciano, J. L. Quon, T. Su, M. M. Taylor, and A. Bordey, "Postnatal neurogenesis generates heterotopias, olfactory micronodules and cortical infiltration following single-cell TSC1 deletion," Human Molecular Genetics, vol. 21, no. 4, pp. 799-810, 2012.

[18] C. A. Lafourcade, T. V. Lin, D. M. Feliciano, L. Zhang, L. S. Hsieh, and A. Bordey, "Rheb activation in subventricular zone progenitors leads to heterotopia, ectopic neuronal differentiation, and rapamycin-sensitive olfactory micronodules and dendrite hypertrophy of newborn neurons," Journal of Neuroscience, vol. 33, no. 6, pp. 2419-2431, 2013.

[19] T. W. Abel, S. J. Baker, M. M. Fraser et al., "Lhermitte-Duclos disease: a report of 31 cases with immunohistochemical analysis of the PTEN/AKT/mTOR pathway," Journal of Neuropathology and Experimental Neurology, vol. 64, no. 4, pp. 341-349, 2005.

[20] R. Sutphen, T. M. Diamond, S. E. Minton, M. Peacocke, H. C. Tsou, and A. W. Root, "Severe Lhermitte-Duclos disease with unique germline mutation of PTEN," The American Journal Medical Genetics, vol. 82, no. 4, pp. 290-293, 1999.

[21] B. W. Luikart, E. Schnell, E. K. Washburn, A. L. Bensen, K. R. Tovar, and G. L. Westbrook, "Pten knockdown in vivo increases excitatory drive onto dentate granule cells," Journal of Neuroscience, vol. 31, no. 11, pp. 4345-4354, 2011.

[22] C. H. Kwon, B. W. Luikart, C. M. Powell et al., "Pten regulates neuronal arborization and social interaction in mice," Neuron, vol. 50, no. 3, pp. 377-388, 2006.

[23] M. M. Fraser, I. T. Bayazitov, S. S. Zakharenko, and S. J. Baker, "Phosphatase and tensin homolog, deleted on chromosome 10 deficiency in brain causes defects in synaptic structure, transmission and plasticity, and myelination abnormalities," Neuroscience, vol. 151, no. 2, pp. 476-488, 2008.

[24] J. Condie, J. Goldstein, and M. S. Wainwright, "Acquired microcephaly, regression of milestones, mitochondrial dysfunction, and episodic rigidity in a 46,XY male with a de Novo MECP2 gene mutation," Journal of Child Neurology, vol. 25, no. 5, pp. 633-636, 2010

[25] E. Takeshita, Y. Saito, E. Nakagawa et al., "Late-onset mental deterioration and fluctuating dystonia in a female patient with 
a truncating MECP2 mutation," Journal of the Neurological Sciences, vol. 308, no. 1-2, pp. 168-172, 2011.

[26] M. Jiang, R. T. Ash, S. A. Baker et al., "Dendritic arborization and spine dynamics are abnormal in the mouse model of MECP2 duplication syndrome," Journal of Neuroscience, vol. 33, no. 50, pp. 19518-19533, 2013.

[27] X. Jin, N. Cui, W. Zhong, and C. Jiang, "GABAergic synaptic inputs of locus coeruleus neurons in wild-type and Mecp2-null mice," American Journal of Physiology and Cell Physiology, vol. 304, no. 9, pp. C844-C857, 2013.

[28] K. W. Thiel and G. Carpenter, "Epidermal growth factor receptor juxtamembrane region regulates allosteric tyrosine kinase activation," Proceedings of the National Academy of Sciences of the United States of America, vol. 104, no. 49, pp. 19238-19243, 2007.

[29] F. Walker, J. Rothacker, C. Henderson et al., "Ligand binding induces a conformational change in epidermal growth factor receptor dimers," Growth Factors, vol. 30, no. 6, pp. 394-409, 2012.

[30] C. A. Ritter, M. Perez-Torres, C. Rinehart et al., "Human breast cancer cells selected for resistance to trastuzumab in vivo overexpress epidermal growth factor receptor and ErbB ligands and remain dependent on the ErbB receptor network," Clinical Cancer Research, vol. 13, no. 16, pp. 4909-4919, 2007.

[31] A. Ahmad, Z. Wang, D. Kong et al., "Platelet-derived growth factor-D contributes to aggressiveness of breast cancer cells by up-regulating Notch and NF- $\kappa \mathrm{B}$ signaling pathways," Breast Cancer Research and Treatment, vol. 126, no. 1, pp. 15-25, 2011.

[32] J. Czopek, J. Pawlęga, K. Fijorek, M. Püsküllüoğlu, and K. Okoń, "HER-3 expression in HER-2-amplified breast carcinoma," Contemporary Oncology, vol. 17, no. 5, pp. 446-449, 2013.

[33] P. Mahzouni and M. Movahedipour, "An immunohistochemical study of HER2 expression in meningioma and its correlation with tumor grade," Pathology Research and Practice, vol. 208, no. 4, pp. 221-224, 2012.

[34] R. Bose, S. M. Kavuri, A. C. Searleman et al., "Activating HER2 mutations in HER2 gene amplification negative breast cancer," Cancer Discovery, vol. 3, no. 2, pp. 224-237, 2013.

[35] V. Serra, A. Vivancos, X. S. Puente et al., "Clinical response to a lapatinib -based therapy for a Li- Fraumeni syndrome patient with a novel HER $2^{V 659 E}$ mutation," Cancer Discovery, vol. 3, no. 11, pp. 1238-1244, 2013.

[36] M. Trajkovic-Arsic, P. Mohajerani, A. Sarantopoulos et al., "Multimodal molecular imaging of integrin $\alpha \mathrm{v} \beta 3$ for in vivo detection of pancreatic cancer," Journal of Nuclear Medicine, vol. 55, no. 3, pp. 446-451, 2014.

[37] R. Li, A. Maminishkis, G. Zahn, D. Vossmeyer, and S. S. Miller, "Integrin $\alpha 5 \beta 1$ mediates attachment, migration, and proliferation in human retinal pigment epithelium: relevance for proliferative retinal disease," Investigative Ophthalmology and Visual Science, vol. 50, no. 12, pp. 5988-5996, 2009.

[38] T. Umemoto, M. Yamato, Y. Shiratsuchi et al., "Expression of integrin $\beta 3$ is correlated to the properties of quiescent hemopoietic stem cells possessing the side population phenotype," Journal of Immunology, vol. 177, no. 11, pp. 7733-7739, 2006.

[39] J. T. Wang, Y. Liu, X. Kan, M. Liu, and J. G. Lu, "Cilengitide, a small molecule antagonist, targeted to integrin $\alpha \nu$ inhibits proliferation and induces apoptosis of laryngeal cancer cells in vitro," European Archives of Otorhinolaringology, vol. 271, no. 8, pp. 2233-2240, 2014.
[40] N. C. Cheng, N. Van Zandwijk, and G. Reid, "Cilengitide inhibits attachment and invasion of malignant pleural mesothelioma cells through antagonism of integrins av $\beta 3$ and av $\beta 5$," PLoS One, vol. 9, no. 3, Article ID e90374, 2014.

[41] A. B. Dydensborg, I. C. Teller, J. F. Groulx et al., "Integrin alpha6Bbeta4 inhibits colon cancer cell proliferation and c-Myc activity," BMC Cancer, vol. 9, no. 223, pp. 1-13, 2009.

[42] M. Kato, N. Yasui, M. Seki et al., "Aggressive transformation of juvenile myelomonocytic leukemia associated with duplication of oncogenic KRAS due to acquired uniparental disomy," Journal of Pediatrics, vol. 162, no. 6, pp. 1285-1288, 2013.

[43] H. Allgayer, D. D. Boyd, M. M. Heiss, E. K. Abdalla, S. A. Curley, and G. E. Gallick, "Activation of src kinase in primary colorectal carcinoma: an indicator of poor clinical prognosis," Cancer, vol. 94, no. 2, pp. 344-351, 2002.

[44] D. Chen, J. F. Huang, K. Liu et al., "BRAF ${ }^{V 600 E}$ mutation and its association with clinicopathological features of colorectal cancer: a systematic review and meta-analysis," PLOS ONE, vol. 9, no. 3, Article ID e90607, 2014.

[45] K. D. Sutherland, J. Y. Song, M. C. Kwon, N. Proost, J. Zevenhoven, and A. Berns, "Multiple cells-of-origin of mutant K-Ras-induced mouse lung adenocarcinoma," Proceedings of the National Academy of Science of the Untied States of America, 2014.

[46] I. P. Serk, J. Zhang, K. A. Phillips et al., “Targeting Src family kinases inhibits growth and lymph node metastases of prostate cancer in an orthotopic nude mouse model," Cancer Research, vol. 68, no. 9, pp. 3323-3333, 2008.

[47] D. Dankort, E. Filenova, M. Collado, M. Serrano, K. Jones, and M. McMahon, "A new mouse model to explore the initiation, progression, and therapy of BRAFV600E-induced lung tumors," Genes \& Development, vol. 21, no. 4, pp. 379-384, 2007.

[48] S. Ely, M. di Liberto, R. Niesvizky et al., "Mutually exclusive cyclin-dependent kinase 4/cyclin D1 and cyclin-dependent kinase 6/cyclin D2 pairing inactivates retinoblastoma protein and promotes cell cycle dysregulation in multiple myeloma," Cancer Research, vol. 65, no. 24, pp. 11345-11353, 2005.

[49] G. H. Xiao, R. Gallagher, J. Shetler et al., "The NF2 tumor suppressor gene product, merlin, inhibits cell proliferation and cell cycle progression by repressing cyclin D1 expression," Molecular and Cellular Biology, vol. 25, no. 6, pp. 2384-2394, 2005.

[50] J. E. Chipuk, J. C. Fisher, C. P. Dillon, R. W. Kriwacki, T. Kuwana, and D. R. Green, "Mechanism of apoptosis induction by inhibition of the anti-apoptotic BCL-2 proteins," Proceedings of the National Academy of Sciences of the United States of America, vol. 105, no. 51, pp. 20327-20332, 2008.

[51] S. R. Datta, H. Dudek, T. Xu et al., "Akt phosphorylation of BAD couples survival signals to the cell- intrinsic death machinery," Cell, vol. 91, no. 2, pp. 231-241, 1997.

[52] Q. She, D. B. Solit, Q. Ye, K. E. O’Reilly, J. Lobo, and N. Rosen, "The BAD protein integrates survival signaling by EGFR/ MAPK and PI3K/Akt kinase pathways in PTEN-deficient tumor cells," Cancer Cell, vol. 8, no. 4, pp. 287-297, 2005.

[53] N. Lau, M. M. Feldkamp, L. Roncari et al., "Loss of neurofibromin is associated with activation of RAS/MAPK and PI3K/AKT signaling in a neurofibromatosis 1 astrocytoma," Journal of Neuropathology \& Experimental Neurology, vol. 59, no. 9, pp. $759-767,2000$

[54] L. Holmgren, A. Glaser, S. Pfeifer-Ohlsson, and R. Ohlsson, "Angiogenesis during human extraembryonic development 
involves the spatiotemporal control of PDGF ligand and receptor gene expression," Development, vol. 113, no. 3, pp. 749-754, 1991.

[55] G. Breier, U. Albrecht, S. Sterrer, and W. Risau, "Expression of vascular endothelial growth factor during embryonic angiogenesis and endothelial cell differentiation," Development, vol. 114, no. 2, pp. 521-532, 1992.

[56] J. Su, P. Yang, J. Shih et al., “The VEGF-C/Flt-4 axis promotes invasion and metastasis of cancer cells," Cancer Cell, vol. 9, no. 3, pp. 209-223, 2006.

[57] P. Young, O. Boussadia, H. Halfter et al., "E-cadherin controls adherens junctions in the epidermis and the renewal of hair follicles," EMBO Journal, vol. 22, no. 21, pp. 5723-5733, 2003.

[58] G. F. Pontoriero, A. N. Smith, L. D. Miller, G. L. Radice, J. A. West-Mays, and R. A. Lang, "Co-operative roles for Ecadherin and $\mathrm{N}$-cadherin during lens vesicle separation and lens epithelial cell survival," Developmental Biology, vol. 326, no. 2, pp. 403-417, 2009.

[59] C. Nagi, M. Guttman, S. Jaffer et al., "N-cadherin expression in breast cancer: correlation with an aggressive histologic variant-invasive micropapillary carcinoma," Breast Cancer Research and Treatment, vol. 94, no. 3, pp. 225-235, 2005.

[60] J. B. Wyckoff, Y. Wang, E. Y. Lin et al., "Direct visualization of macrophage-assisted tumor cell intravasation in mammary tumors," Cancer Research, vol. 67, no. 6, pp. 2649-2656, 2007.

[61] Z. Fu, Y. Kitagawa, R. Shen et al., "Metastasis suppressor gene Raf kinase inhibitor protein (RKIP) is a novel prognostic marker in prostate cancer," Prostate, vol. 66, no. 3, pp. 248-256, 2006.

[62] H. C. Lee, B. Tian, J. M. Sedivy, J. R. Wands, and M. Kim, "Loss of Raf kinase inhibitor protein promotes cell proliferation and migration of human hepatoma cells," Gastroenterology, vol. 131, no. 4, pp. 1208-1217, 2006.

[63] M. Bizzarri, A. Pasqualato, A. Cucina, and V. Pasta, "Physical forces and non linear dynamics mould fractal cell shape: quantitative morphological parameters and cell phenotype," Histology and Histopathology, vol. 28, no. 2, pp. 155-174, 2013.

[64] A. M. Soto, M. V. Maffini, and C. Sonnenschein, "Neoplasia as development gone awry: the role of endocrine disruptors," International Journal of Andrology, vol. 31, no. 2, pp. 288-292, 2008.

[65] N. A. Charles, E. C. Holland, R. Gilbertson, R. Glass, and H. Kettenmann, "The brain tumor microenvironment," GLIA, vol. 60, no. 3, pp. 502-514, 2012.

[66] M. J. Bissell and W. C. Hines, "Why don't we get more cancer? A proposed role of the microenvironment in restraining cancer progression," Nature Medicine, vol. 17, no. 3, pp. 320-329, 2011.

[67] S. M. Pyonteck, L. Akkari, A. J. Schuhmacher et al., "CSF-1R inhibition alters macrophage polarization and blocks glioma progression," Nature Medicine, vol. 19, no. 10, pp. 1264-1272, 2013.

[68] D. W. Infanger, Y. Cho, B. S. Lopez et al., "Glioblastoma stem cells are regulated by interleukin- 8 signaling in a tumoral perivascular niche," Cancer Research, vol. 73, no. 23, pp. 70797089, 2013.

[69] J. J. Phillips, "Novel therapeutic targets in the brain tumor microenvironment," Oncotarget, vol. 3, no. 5, pp. 568-575, 2012.

[70] J. M. Heddleston, M. Hitomi, M. Venere et al., "Glioma stem cell maintenance: the role of the microenvironment," Current Pharmaceutical Design, vol. 17, no. 23, pp. 2386-2401, 2011.
[71] M. Lammert, J. M. Friedman, L. Kluwe, and V. F. Mautner, "Prevalence of neurofibromatosis 1 in German children at elementary school enrollment," Archives of Dermatology, vol. 141, no. 1, pp. 71-74, 2005.

[72] A. G. Knudson Jr., "Mutation and cancer: statistical study of retinoblastoma.," Proceedings of the National Academy of Sciences of the United States of America, vol. 68, no. 4, pp. 820$823,1971$.

[73] L. Segal, M. Darvish-Zargar, M. Dilenge, J. Ortenberg, and R. C. Polomeno, "Optic pathway gliomas in patients with neurofibromatosis type 1: follow-up of 44 patients," Journal of the American Association for Pediatric Ophthalmology and Strabismus, vol. 14, no. 2, pp. 155-158, 2010.

[74] V. F. Mautner, M. Hartmann, L. Kluwe, R. E. Friedrich, and C. Fünsterer, "MRI growth patterns of plexiform neurofibromas in patients with neurofibromatosis type 1," Neuroradiology, vol. 48, no. 3, pp. 160-165, 2006.

[75] W. Brenner, R. E. Friedrich, K. A. Gawad et al., "Prognostic relevance of FDG PET in patients with neurofibromatosis type1 and malignant peripheral nerve sheath tumours," European Journal of Nuclear Medicine and Molecular Imaging, vol. 33, no. 4, pp. 428-432, 2006.

[76] S. R. Plotkin, M. A. Bredella, W. Cai et al., "Quantitative assessment of whole-body tumor burden in adult patients with neurofibromatosis," PLoS ONE, vol. 7, no. 4, Article ID e35711, 2012.

[77] E. Dombi, J. Solomon, A. J. Gillespie et al., "NF1 plexiform neurofibroma growth rate by volumetric MRI: relationship to age and body weight," Neurology, vol. 68, no. 9, pp. 643-647, 2007.

[78] R. Nguyen, K. Jett, G. J. Harris, W. Cai, J. M. Friedman, and V. F. Mautner, "Benign whole body tumor volume is a risk factor for malignant peripheral nerve sheath tumors in neurofibromatosis type 1," Journal of Neurooncology, vol. 116, no. 2, pp. 307-313, 2014.

[79] C. Zou, K. D. Smith, J. Liu et al., "Clinical, pathological, and molecular variables predictive of malignant peripheral nerve sheath tumor outcome," Annals of Surgery, vol. 249, no. 6, pp. 1014-1022, 2009.

[80] D. A. Marchuk, A. M. Saulino, R. Tavakkol et al., "cDNA cloning of the type 1 neurofibromatosis gene: complete sequence of the NF1 gene product," Genomics, vol. 11, no. 4, pp. 931-940, 1991.

[81] M. R. Wallace, D. A. Marchuk, L. B. Andersen et al., "Type 1 neurofibromatosis gene: Identification of a large transcript disrupted in three NF1 patients," Science, vol. 249, no. 4965, pp. 181-186, 1990.

[82] L. B. Andersen, R. Ballester, D. A. Marchuk et al., "A conserved alternative splice in the von Recklinghausen neurofibromatosis (NF1) gene produces two neurofibromin isoforms, both of which have GTPase- activating protein activity," Molecular and Cellular Biology, vol. 13, no. 1, pp. 487-495, 1993.

[83] R. M. Costa, T. Yang, D. P. Huynh et al., "Learning deficits, but normal development and tumor predisposition, in mice lacking exon 23a of Nf1," Nature Genetics, vol. 27, no. 4, pp. 399-405, 2001.

[84] D. H. Gutmann, R. T. Geist, D. E. Wright, and W. D. Snider, "Expression of the neurofibromatosis 1 (NF1) isoforms in developing and adult rat tissues," Cell Growth and Differentiation, vol. 6, no. 3, pp. 315-323, 1995.

[85] D. H. Gutmann, Y. Zhang, and A. Hirbe, "Developmental regulation of a neuron-specific neurofibromatosis 1 isoform," Annals of Neurology, vol. 46, no. 5, pp. 777-782, 1999. 
[86] G. Xu, P. O'Connell, D. Viskochil et al., "The neurofibromatosis type 1 gene encodes a protein related to GAP," Cell, vol. 62, no. 3, pp. 599-608, 1990.

[87] C. M. Johannessen, E. E. Reczek, M. F. James, H. Brems, E. Legius, and K. Cichowski, "The NF1 tumor suppressor critically regulates TSC2 and mTOR," Proceedings of the National Academy of Sciences of the United States of America, vol. 102, no. 24, pp. 8573-8578, 2005.

[88] S. Banerjee, N. R. Crouse, R. J. Emnett, S. M. Gianino, and D. H. Gutmann, "Neurofibromatosis-1 regulates mTOR-mediated astrocyte growth and glioma formation in a TSC/Rhebindependent manner," Proceedings of the National Academy of Sciences of the United States of America, vol. 108, no. 38, pp. 15996-16001, 2011.

[89] D. Y. Lee, T. H. Yeh, R. J. Emnett, C. R. White, and D. H. Gutmann, "Neurofibromatosis-1 regulates neuroglial progenitor proliferation and glial differentiation in a brain regionspecific manner," Genes \& Development, vol. 24, no. 20, pp. 23172329, 2010.

[90] H. F. Guo, J. Tong, F. Hannan, L. Luo, and Y. Zhong, "A neurofibromatosis-1-regulated pathway is required for learning in Drosophila," Nature, vol. 403, no. 6772, pp. 895-898, 2000.

[91] B. Dasgupta, L. L. Dugan, and D. H. Gutmann, "The neurofibromatosis 1 gene product neurofibromin regulates pituitary adenylate cyclase-activating polypeptide-mediated signaling in astrocytes," Journal of Neuroscience, vol. 23, no. 26, pp. 89498954, 2003.

[92] J. A. Brown, S. M. Gianino, and D. H. Gutmann, "Defective cAMP generation underlies the sensitivity of CNS neurons to neurofibromatosis-1 heterozygosity," Journal of Neuroscience, vol. 30, no. 16, pp. 5579-5589, 2010.

[93] W. W. Pong and D. H. Gutmann, “The ecology of brain tumors: lessons learned from neurofibromatosis-1," Oncogene, vol. 30, no. 10, pp. 1135-1146, 2011.

[94] Y. Zhu, P. Ghosh, P. Charnay, D. K. Burns, and L. F. Parada, "Neurofibromas in NF1: Schwann cell origin and role of tumor environment," Science, vol. 296, no. 5569, pp. 920-922, 2002.

[95] M. L. Bajenaru, Y. Zhu, N. M. Hedrick, J. Donahoe, L. F. Parada, and D. H. Gutmann, "Astrocyte-specific inactivation of the neurofibromatosis 1 gene (NF1) is insufficient for astrocytoma formation," Molecular and Cellular Biology, vol. 22, no. 14, pp. 5100-5113, 2002.

[96] M. L. Bajenaru, M. R. Hernandez, A. Perry et al., "Optic nerve glioma in mice requires astrocyte $\mathrm{Nf1}$ gene inactivation and $\mathrm{Nf1}$ brain heterozygosity," Cancer Research, vol. 63, no. 24, pp. 85738577, 2003.

[97] F. C. Yang, S. Chen, T. Clegg et al., "Nf1+/- mast cells induce neurofibroma like phenotypes through secreted TGF- $\beta$ signaling," Human Molecular Genetics, vol. 15, no. 16, pp. 2421-2437, 2006.

[98] F. Yang, D. A. Ingram, S. Chen et al., "Nf1-dependent tumors require a microenvironment containing $\mathrm{Nf1+} /-$ and c-kitdependent bone marrow," Cell, vol. 135, no. 3, pp. 437-448, 2008.

[99] G. C. Daginakatte and D. H. Gutmann, "Neurofibromatosis1 (Nf1) heterozygous brain microglia elaborate paracrine factors that promote Nf1-deficient astrocyte and glioma growth," Human Molecular Genetics, vol. 16, no. 9, pp. 1098-1112, 2007.

[100] G. C. Daginakatte, S. M. Gianino, N. W. Zhao, A. S. Parsadanian, and D. H. Gutmann, "Increased c-Jun-NH2-kinase signaling in neurofibromatosis-1 heterozygous microglia drives microglia activation and promotes optic glioma proliferation," Cancer Research, vol. 68, no. 24, pp. 10358-10366, 2008.
[101] W. W. Pong, S. B. Higer, S. M. Gianino, R. J. Emnett, and D. H. Gutmann, "Reduced microglial CX3CR1 expression delays neurofibromatosis-1 glioma formation," Annals of Neurology, vol. 73, no. 2, pp. 303-308, 2013.

[102] N. M. Warrington, S. M. Gianino, E. Jackson et al., "Cyclic AMP suppression is sufficient to induce gliomagenesis in a mouse model of neurofibromatosis-1," Cancer Research, vol. 70, no. 14, pp. 5717-5727, 2010.

[103] C. I. Brannan, A. S. Perkins, K. S. Vogel et al., "Targeted disruption of the neurofibromatosis type-1 gene leads to developmental abnormalities in heart and various neural crestderived tissues," Genes \& Development, vol. 8, no. 9, pp. 10191029, 1994.

[104] I. The, G. E. Hannigan, G. S. Cowley et al., "Rescue of a Drosophila NF1 mutant phenotype by protein kinase A," Science, vol. 276, no. 5313, pp. 791-794, 1997.

[105] J. Tong, F. Hannan, Y. Zhu, A. Bernards, and Y. Zhong, "Neurofibromin regulates $G$ protein-stimulated adenylyl cyclase activity," Nature Neuroscience, vol. 5, no. 2, pp. 95-96, 2002.

[106] J. A. Brown, K. A. Diggs-Andrews, S. M. Gianino, and D. H. Gutmann, "Neurofibromatosis-1 heterozygosity impairs CNS neuronal morphology in a cAMP/PKA/ROCK-dependent manner," Molecular and Cellular Neuroscience, vol. 49, no. 1, pp. 13-22, 2012.

[107] B. Hegedus, B. Dasgupta, J. E. Shin et al., "Neurofibromatosis-1 regulates neuronal and glial cell differentiation from neuroglial progenitors in vivo by both cAMP- and Ras-dependent mechanisms," Cell Stem Cell, vol. 1, no. 4, pp. 443-457, 2007.

[108] B. Dasgupta and D. H. Gutmann, "Neurofibromin regulates neural stem cell proliferation, survival, and astroglial differentiation in vitro and in vivo," Journal of Neuroscience, vol. 25, no. 23, pp. 5584-5594, 2005.

[109] N. M. Joseph, J. T. Mosher, J. Buchstaller et al., "The loss of Nf1 transiently promotes self-renewal but not tumorigenesis by neural crest stem cells," Cancer Cell, vol. 13, no. 2, pp. 129-140, 2008.

[110] M. E. Lush, Y. Li, C. Kwon, J. Chen, and L. F. Parada, "Neurofibromin is required for barrel formation in the mouse somatosensory cortex," Journal of Neuroscience, vol. 28, no. 7, pp. 1580-1587, 2008.

[111] Y. Zhu, M. I. Romero, P. Ghosh et al., "Ablation of NF1 function in neurons induces abnormal development of cerebral cortex and reactive gliosis in the brain," Genes and Development, vol. 15, no. 7, pp. 859-876, 2001.

[112] Z. Li, Y. Zhang, E. Wang et al., "Intracranial clear cell meningioma in two children with blood relations: two case reports and literature review," Child's Nervous System, vol. 28, no. 12, pp. 2143-2151, 2012.

[113] E. Matyja, P. Kunert, W. Grajkowska, and A. Marchel, "Coexistence of meningioma and schwannoma in the same cerebellopontine angle in a patients with NF2," Folia Neuropathologica, vol. 50, no. 2, pp. 166-175, 2012.

[114] M. Tabernero, M. Jara-Acevedo, A. B. Nieto et al., "Association between mutation of the NF2 gene and monosomy 22 in menopausal women with sporadic meningiomas," BMC Medical Genetics, vol. 14, article 114, 2013.

[115] M. D. Begnami, M. Palau, E. J. Rushing, M. Santi, and M. Quezado, "Evaluation of NF2 gene deletion in sporadic schwannomas, meningiomas, and ependymomas by chromogenic in situ hybridization," Human Pathology, vol. 38, no. 9, pp. 13451350, 2007. 
[116] L. Lassaletta, M. Torres-Martín, C. Peña-Granero et al., "NF2 genetic alterations in sporadic vestibular schwannomas: Clinical implications," Otology and Neurotology, vol. 34, no. 7, pp. 1355-1361, 2013.

[117] R. H. Lekanne Deprez, A. B. Bianchi, N. A. Groen et al., "Frequent NF2 gene transcript mutations in sporadic meningiomas and vestibular schwannomas," The American Journal of Human Genetics, vol. 54, no. 6, pp. 1022-1029, 1994.

[118] P. K. Singh, D. H. Gutmann, C. E. Fuller, I. F. Newsham, and A. Perry, "Differential involvement of protein 4.1 family members DAL-1 and NF2 in intracranial and intraspinal ependymomas," Modern Pathology, vol. 15, no. 5, pp. 526-531, 2002.

[119] G. A. Rouleau, P. Merel, M. Lutchman et al., "Alteration in a new gene encoding a putative membrane-organizing protein causes neuro-fibromatosis type 2," Nature, vol. 363, no. 6429, pp. 515$521,1993$.

[120] J. A. Trofatter, M. M. MacCollin, J. L. Rutter et al., "A novel moesin-, ezrin-, radixin-like gene is a candidate for the neurofibromatosis 2 tumor suppressor," Cell, vol. 72, no. 5, pp. 791-800, 1993.

[121] N. Sato, N. Funayama, A. Nagafuchi, S. Yonemura, and S. Tsukita, "A gene family consisting of ezrin, radixin and moesin. Its specific localization at actin filament/plasma membrane association sites," Journal of Cell Science, vol. 103, no. 1, pp. 131$143,1992$.

[122] D. H. Gutmann, D. E. Wright, R. T. Geist, and W. D. Snider, "Expression of the neurofibromatosis 2 (NF2) gene isoforms during rat embryonic development," Human Molecular Genetics, vol. 4, no. 3, pp. 471-478, 1995.

[123] V. H. Haase, J. A. Trofatter, M. MacCollin, E. Tarttelin, J. F. Gusella, and V. Ramesh, "The murine NF2 homologue encodes a highly conserved merlin protein with alternative forms," Human Molecular Genetics, vol. 3, no. 3, pp. 407-411, 1994.

[124] L. Sherman, H. Xu, R. T. Geist et al., "Interdomain binding mediates tumor growth suppression by the NF2 gene product," Oncogene, vol. 15, no. 20, pp. 2505-2509, 1997.

[125] A. Schulz, K. J. Geissler, S. Kumar, G. Leichsenring, H. Morrison, and S. L. Baader, "Merlin inhibits neurite outgrowth in the CNS," Journal of Neuroscience, vol. 30, no. 30, pp. 10177-10186, 2010.

[126] A. Schulz, S. L. Baader, M. Niwa-Kawakita et al., "Merlin isoform 2 in neurofibromatosis type 2-associated polyneuropathy," Nature Neuroscience, vol. 16, no. 4, pp. 426-433, 2013.

[127] R. Rong, E. I. Surace, C. A. Haipek, D. H. Gutmann, and K. Ye, "Serine 518 phosphorylation modulates merlin intramolecular association and binding to critical effectors important for NF2 growth suppression," Oncogene, vol. 23, no. 52, pp. 8447-8454, 2004.

[128] R. J. Shaw, J. G. Paez, M. Curto et al., "The Nf2 tumor suppressor merlin, functions in Rac-dependent signaling," Developmental Cell, vol. 1, no. 1, pp. 63-72, 2001.

[129] D. Lallemand, M. Curto, I. Saotome, M. Giovannini, and A. I. McClatchey, "NF2 deficiency promotes tumorigenesis and metastasis by destabilizing adherens junctions," Genes and Development, vol. 17, no. 9, pp. 1090-1100, 2003.

[130] D. H. Gutmann, L. Sherman, L. Seftor, C. Haipek, K. H. Lu, and M. Hendrix, "Increased expression of the NF2 tumor suppressor gene product, merlin, impairs cell motility, adhesion and spreading," Human Molecular Genetics, vol. 8, no. 2, pp. 267-275, 1999.

[131] M. Curto, B. K. Cole, D. Lallemand, C. Liu, and A. I. McClatchey, "Contact-dependent inhibition of EGFR signaling by Nf2/Merlin," Journal of Cell Biology, vol. 177, no. 5, pp. $893-$ 903, 2007.

[132] T. Okada, M. Lopez-Lago, and F. G. Giancotti, "Merlin/NF-2 mediates contact inhibition of growth by suppressing recruitment of Rac to the plasma membrane," Journal of Cell Biology, vol. 171, no. 2, pp. 361-371, 2005.

[133] S. S. Houshmandi, R. J. Emnett, M. Giovannini, and D. H. Gutmann, "The neurofibromatosis 2 protein, merlin, regulates glial cell growth in an ErbB2- and Src-dependent manner," Molecular and Cellular Biology, vol. 29, no. 6, pp. 1472-1486, 2009.

[134] A. I. McClatchey and R. G. Fehon, "Merlin and the ERM proteins-regulators of receptor distribution and signaling at the cell cortex," Trends in Cell Biology, vol. 19, no. 5, pp. 198-206, 2009.

[135] H. Morrison, T. Sperka, J. Manent, M. Giovannini, H. Ponta, and P. Herrlich, "Merlin/neurofibromatosis type 2 suppresses growth by inhibiting the activation of Ras and Rac," Cancer Research, vol. 67, no. 2, pp. 520-527, 2007.

[136] A. J. Ridley, H. F. Paterson, C. L. Johnston, D. Diekmann, and A. Hall, "The small GTP-binding protein rac regulates growth factor-induced membrane ruffling," Cell, vol. 70, no. 3, pp. 401410, 1992.

[137] M. R. Silvis, B. T. Kreger, W. Lien et al., " $\alpha$-catenin is a tumor suppressor that controls cell accumulation by regulating the localization and activity of the transcriptional coactivator Yap1," Science Signaling, vol. 4, no. 174, pp. 1-10, 2011.

[138] T. Mizuno, H. Murakami, M. Fujii et al., "YAP induces malignant mesothelioma cell proliferation by upregulating transcription of cell cycle-promoting genes," Oncogene, vol. 31, no. 49, pp. 5117-5122, 2012.

[139] D. H. Kim, S. H. Kim, O. J. Lee et al., "Differential expression of Yes-associated protein and phosphorylated Yes-associated protein is correlated with expression of Ki-67 and phospho-ERK in colorectal adenocarcinoma," Histology and Histopathology, vol. 28, no. 11, pp. 1483-1490, 2013.

[140] K. Striedinger, S. R. VandenBerg, G. S. Baia, M. W. McDermott, D. H. Gutmann, and A. Lal, "The neurofibromatosis 2 tumor suppressor gene product, merlin, regulates human meningioma cell growth by signaling through YAP," Neoplasia, vol. 10, no. 11, pp. 1204-1212, 2008.

[141] N. Zhang, H. Bai, K. K. David et al., “The Merlin /NF2 tumor suppressor functions through the YAP oncoprotein to regulate tissue homeostasis in mammals," Developmental Cell, vol. 19, no. 1, pp. 27-38, 2010.

[142] A. I. McClatchey, I. Saotome, V. Ramesh, J. F. Gusella, and T. Jacks, "The Nf2 tumor suppressor gene product is essential for extraembryonic development immediately prior to gastrulation," Genes \& Development, vol. 11, no. 10, pp. 1253-1265, 1997.

[143] D. R. LaJeunesse, B. M. McCartney, and R. G. Fehon, "Structural analysis of Drosophila Merlin reveals functional domains important for growth control and subcellular localization," Journal of Cell Biology, vol. 141, no. 7, pp. 1589-1599, 1998.

[144] F. Hamaratoglu, M. Willecke, M. Kango-Singh et al., "The tumour-suppressor genes NF2/Merlin and Expanded act through Hippo signalling to regulate cell proliferation and apoptosis," Nature Cell Biology, vol. 8, no. 1, pp. 27-36, 2006.

[145] J. Larsson, M. Ohishi, B. Garrison et al., "Nf2/merlin regulates hematopoietic stem cell behavior by altering microenvironmental architecture," Cell Stem Cell, vol. 3, no. 2, pp. 221-227, 2008 . 
[146] S. Benhamouche, M. Curto, I. Saotome et al., "Nf2/Merlin controls progenitor homeostasis and tumorigenesis in the liver," Genes \& Development, vol. 24, no. 16, pp. 1718-1730, 2010.

[147] A. Lavado, Y. He, J. Paré et al., “Tumor suppressor Nf2 limits expansion of the neural progenitor pool by inhibiting Yap/Taz transcriptional coactivators," Development, vol. 140, no. 16, pp. 3323-3334, 2013.

[148] Y. Benninger, T. Thurnherr, J. A. Pereira et al., "Essential and distinct roles for cdc42 and racl in the regulation of Schwann cell biology during peripheral nervous system development," Journal of Cell Biology, vol. 177, no. 6, pp. 1051-1061, 2007.

[149] C. Tep, M. L. Kim, L. I. Opincariu et al., "Brain-derived neurotrophic factor (BDNF) induces polarized signaling of small GTPase (Racl) protein at the onset of schwann cell myelination through partitioning-defective 3 (Par3) protein," The Journal of Biological Chemistry, vol. 287, no. 2, pp. 16001608, 2012.

[150] A. Nodari, D. Zambroni, A. Quattrini et al., "Beta 1 integrin activates Racl in Schwann cells to generate radial lamellae during axonal sorting and myelination," Journal of Cell Biology, vol. 177, no. 6, pp. 1063-1075, 2007.

[151] L. Guo, C. Moon, K. Niehaus, Y. Zheng, and N. Ratner, "Racl controls schwann cell myelination through cAMP and NF2/merlin," Journal of Neuroscience, vol. 32, no. 48, pp. 1725117261, 2012. 

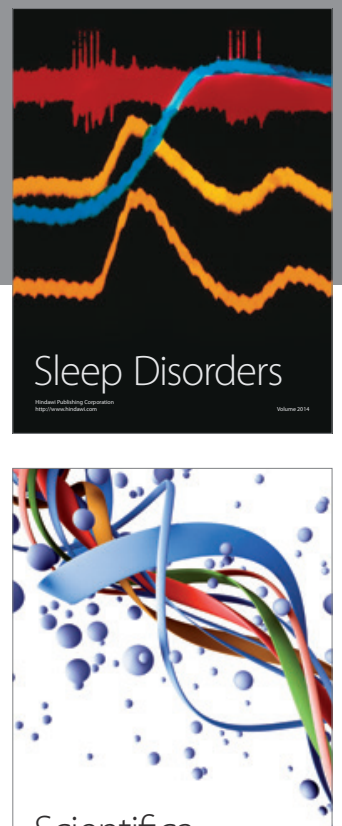

Scientifica
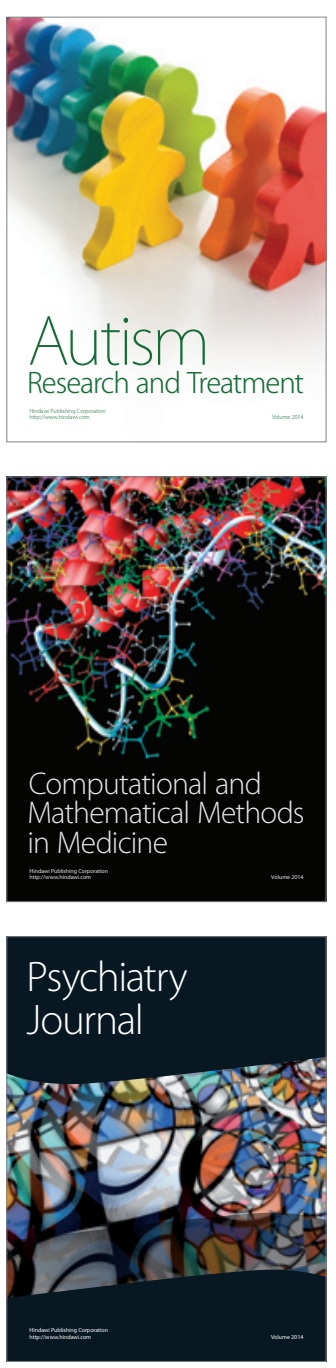
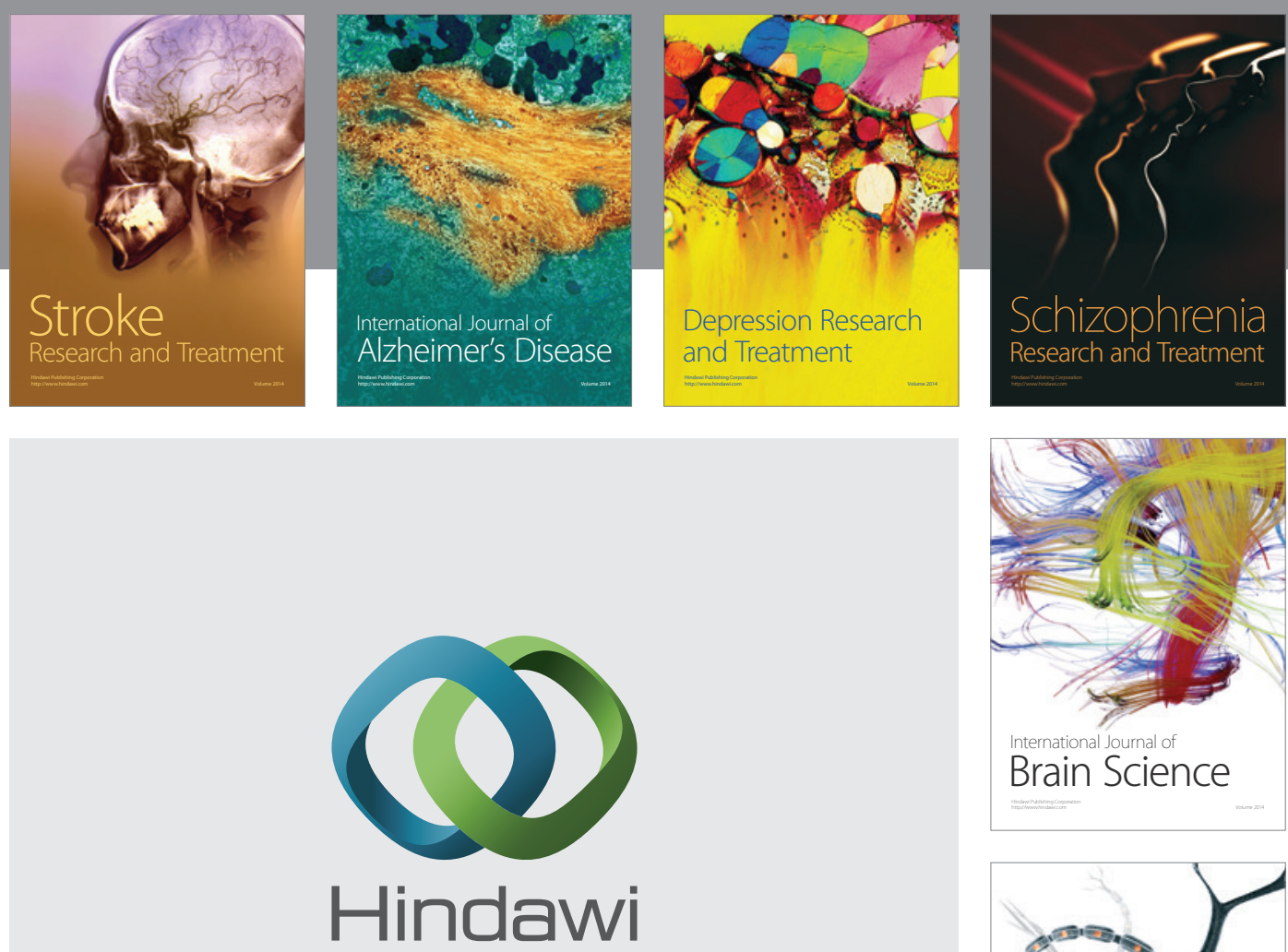

Submit your manuscripts at

http://www.hindawi.com
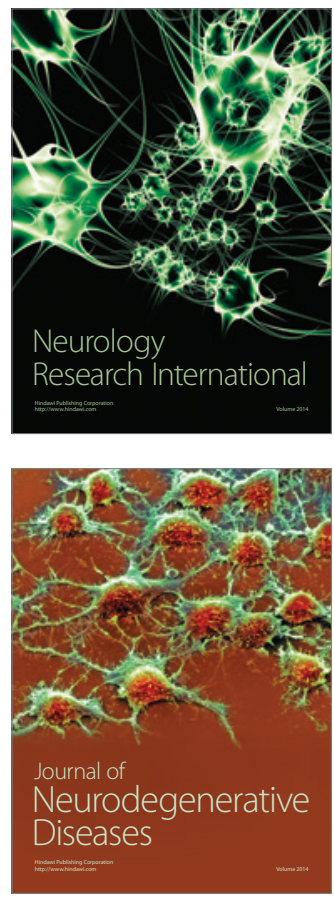

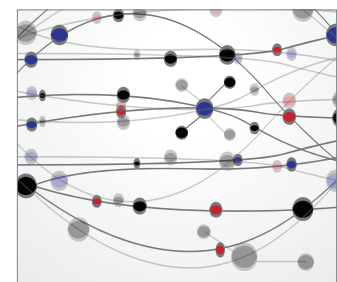

The Scientific World Journal
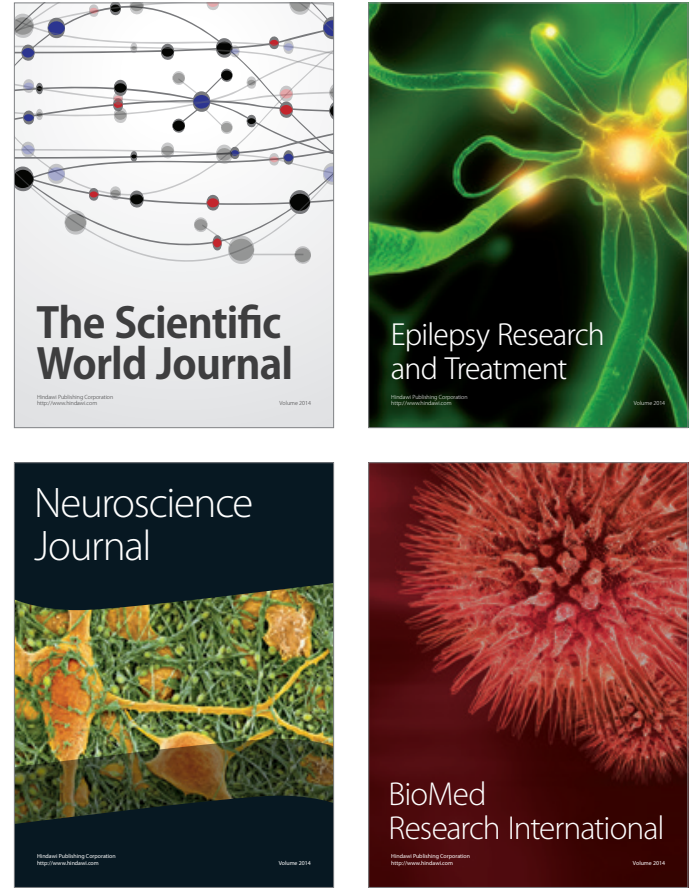

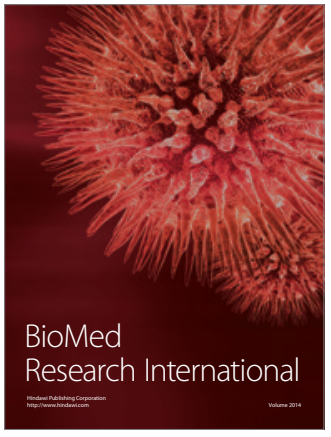

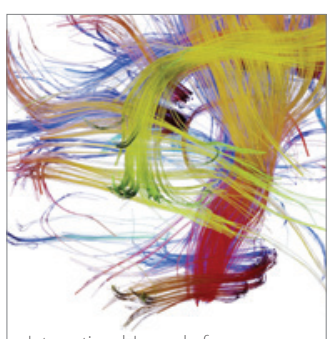

Brain Science

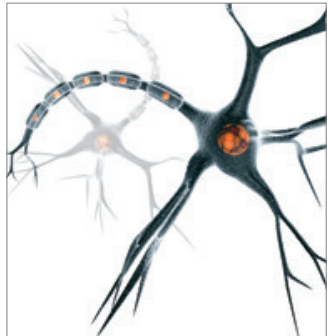

Neural Plasticity
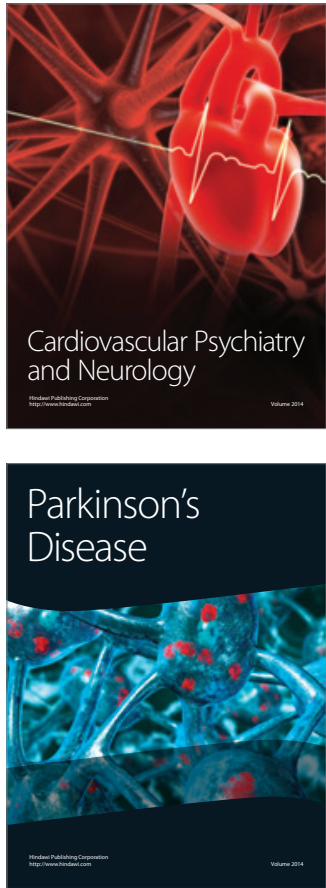